\title{
Homeless Interactions with the Built Environment: A Spatial Pattern Language of Abandoned Housing
}

\author{
Abram Kaplan ${ }^{1}$, Kim Diver ${ }^{2, *}$, Karl Sandin $^{3}$ and Sarah Kafer Mill ${ }^{4}$ \\ 1 Environmental Studies Program, Denison University, Granville, OH 43023, USA; kaplan@denison.edu \\ 2 Department of Earth \& Environmental Sciences, Wesleyan University, Middletown, CT 06459, USA \\ 3 Art History \& Visual Culture Program, Denison University, Granville, OH 43023, USA; sandin@denison.edu \\ 4 Denison University, Granville, OH 43023, USA; sarahkmill@gmail.com \\ * Correspondence: kdiver@wesleyan.edu
}

Received: 30 May 2019; Accepted: 22 June 2019; Published: 25 June 2019

check for updates

\begin{abstract}
Research demonstrates that homeless individuals use urban space in adaptive and endemic ways. Investigations at city and neighborhood scales would benefit from attention to homeless use of abandoned housing. We employ the pattern language approach developed by Christopher Alexander for twenty-two abandoned houses in Newark, Ohio. We use statistical and geospatial data analyses to evaluate hypotheses related to prospect and refuge site qualities, accessibility, and attractiveness to homeless persons, and the proximity of sites to resources. Factors related to prospect/refuge, accessibility, and resource proximity were consistent with the hypotheses. Results can be grouped into four distinct patterns: 'Hiding Places,' 'Welcome Mat,' 'Shelter (Un)becoming,' and 'Proximity to Resources.' Based on these patterns, we conclude with recommendations for officials and organizations addressing homelessness.
\end{abstract}

Keywords: abandoned housing; GIS; homeless; pattern language; urban space

\section{Introduction}

Spaces in the built environment, when consciously designed, always have an intended audience: house dwellers, store shoppers, sidewalk users, and cars on a street. Inevitably, spaces bring unintended audiences as well: neighbors, unexpected shoppers, electric scooters, and autonomous cars. Too often, our urban designs ignore critical populations where a little foresight makes a difference. When civil society fails to recognize such populations, it erodes public space-hardening boundaries between intended and unintended, included and excluded, and conformity and difference [1,2]. Suburban development manifests these deficiencies by eliminating non-motorized access to basic services, displacing residential lives from professional lives, and creating tremendous unintended consequences for community and neighborliness. Those who face severe challenges, for example, in housing, employment, transportation, illness, or family life are impaired in their ability to function in direct relation to the planned environment in which they exist. This is an untenable situation, most poignantly for the homeless [3-5]. For them, a sustaining environment, as Okwui Enwezor asserts, "is never a given. It must constantly be produced...as a fundamental part of civil society." [6,7].

Towards such a spatial production, this study employs a spatial pattern language, informed by field observations and spatial analyses of homeless spaces, to examine patterns of abandoned housing use by homeless populations in a small Midwestern city. By recognizing the use of urban spaces by the homeless, we can learn important lessons about better urban planning to care for a broader base of humanity, creating genuinely social spaces of multiplicity, simultaneity, and diversity [8,9]. It is our hope to demonstrate how local governments and non-profit agencies might better understand spatial patterns of the homeless to improve their well-being-and to not impair their functioning [10]. 
In recent years, research on homelessness in North America has touched upon characteristic ways homeless populations utilize the built environment. Geisler [11] and Perry [12] examined the use of libraries and private businesses as urban hybrid spaces allowing homeless persons to maintain a non-homeless persona while simultaneously seeking shelter. Similarly, hidden spaces such as alleyways can serve as identity forming spaces as well as squatting places $[13,14]$. Attending to physical details of urban life, Hopper [3] described how the homeless use New York City's parks, alleys, steam tunnels, and airports for daily survival. Works by Snow and colleagues [15-17] focused on sheltering patterns and local resource use by homeless individuals in Austin, Tucson, and Los Angeles with similar specificity. Speer [18] and Wagner [19] focused on use of city public space in relation to resource use and social organization among homeless users. Stuart [20] examined differences among policing of homelessness in prime versus marginal urban spaces. Focusing on urban parks and marginal spaces, research has employed theories concerning dominant strategies of urban space control by those in authority versus localized tactics of resistance by the powerless, following Lefebvre, Foucault, Soja, and Harvey (e.g., [21-25]). The authors examined spatial responses by homeless persons when faced with exclusion, repression, and displacement. In public areas, homeless resistance tactics often had powerful spatial components, such as incorporating alternative social networks, mobility, and subverting boundaries. Within similar theoretical frameworks, Maxwell [26] examined squatting strategies in Baltimore's vacant public housing, Phillips and Hamilton [27] investigated the Mad Housers' efforts to assist unsheltered homeless squatting on the periphery of Atlanta, and Rameau $[28,29]$ discusses the Take Back the Land organization's shantytown in Miami and illegal movement of homeless families into vacant houses. The common thread in these studies is the tremendous creativity demonstrated by the homeless as they exploit a variety of sites within the urban built environment to survive overnight, congregate during the day, and even to 'make place' [25].

One key issue in existing studies is the need to increase researchers' understanding of the physical particularities of sites of homeless refuge and use, and the commonalities between them, in relation to their patterns of use by homeless. We seek to understand why certain abandoned structures within the urban fabric are used as homeless squats while similar structures are unutilized. We identify markers of architectonic form and nearby landscape to which homeless are sensitive. We suggest that relating homeless individuals' use of space to specific sites and structures, to particular materials, and to nuances of adjacencies and proximities will capture recurrent spatial patterns that begin to meet this need. In exploring spatial patterns of structure use in terms of abandoned housing characteristics and resource proximity, we develop language by which patterns of spatial behavior can be described and analyzed. If there has been one innovation in reformulating our ability to see and describe spatial behavior, it is the "pattern language" of Christopher Alexander and his team [30]. Alexander's approach emphasizes a local, place-based architecture, a people-friendly means to endemic design. This language reframes conventional notions of design, focusing attention less on the "what" of architectural form, and more on the "why" of spatial relationships [31]. In A Pattern Language, Alexander's team provided a series of 253 individual patterns that re-conceptualized the design process in tangible and specific ways. Alexander's pattern language has not, to our knowledge, been extended to encompass unique behaviors of the homeless. By looking at abandoned houses in relation to their environment, we can investigate aspects of homeless urban space utilization in new ways.

We began with four basic hypotheses regarding patterns of site selection by homeless individuals. The hypotheses focus on four critical dimensions of homeless spatial behavior: prospect/refuge, accessibility, attractiveness, and resource availability.

Hypothesis $\mathbf{1}\left(\mathbf{H}_{\mathbf{1}}\right)$. Prospect and refuge predict abandoned house site selection.

Prospect-refuge theory [32] suggests an innate preference for certain types of shelter (i.e., those with a view) that could carry weight in homeless sheltering strategies. An adaptive shelter choice would seek to maximize both the protective boundaries of safe enclosure and the ability to see broadly 
to the horizon. We expect homeless individuals to seek out shelter opportunities which maximize their prospect (the ability to see and sense potential threats) and refuge (protection from threats, including weather).

Hypothesis $\mathbf{2}\left(\mathbf{H}_{\mathbf{2}} \mathbf{)}\right.$. Accessibility is a necessary attribute of abandoned houses used as homeless shelters.

Abandoned houses which maximize ease of access into the structure will more likely be employed by homeless individuals than sites which offer obstacles. Functional locks and boarded up windows serve as disincentives to people who want to encounter minimal impediments for the basic need of a dry place to sleep.

Hypothesis $\mathbf{3}\left(\mathbf{H}_{3}\right)$. Evidence of (un)attractiveness serves as essential cues to homeless shelter-seekers.

Homeless individuals will make greater use of abandoned sites offering clear signs of attractiveness: evidence of deterioration, unmanaged vegetation, and poor maintenance. In this study, attractiveness does not refer to an aesthetic preference but rather the functional value of adequately meeting one's needs for safety and shelter. For example, we expect that broken windows in a vacant house will be attractive to homeless persons as a signal that a house is truly abandoned.

Hypothesis $\left.4 \mathbf{(} \mathbf{H}_{4}\right)$. Homeless people are more likely to find shelter that is proximate to basic survival resources.

We hypothesize that homeless people, who are often constrained in their transportation choices, are more likely to seek shelter in locations proximate to basic resources. Availability of food, medical services, employment, and other services are relevant to this issue, and are likely to be relevant in different combinations based on the particular needs of an individual.

\section{Materials and Methods}

This study focuses on sites within the urban fabric of Newark, Ohio. Newark is an urban area of approximately 50,000 persons located 35 miles east of metropolitan Columbus. Construction projects over the last few decades, including a multilane highway, have bisected parts of the city, leaving certain residential areas detached from the core and exacerbating problems of marginal housing and homelessness. Although Newark's homeless population utilizes both permanent and temporary structures (e.g., alleys, bridge abutments, wooded areas), this study focuses on abandoned houses. Vacant houses as homeless squats are pertinent throughout the economic climate of increased home foreclosures leading up to the Great Recession. Eleven houses with documented homeless use during 2004 and 2005 were selected based on one of the author's (Sandin) interviews with homeless persons, emergency shelter residents, and local authorities as well as through participation on the Licking County Coalition for Housing's (LCCH) point-in-time homeless population count planning subcommittee. The counts complied with HUD and Ohio Department of Development mandates. LCCH provided a list of eleven abandoned houses not used by homeless persons as a comparison sample.

Data regarding location, characteristics, and intensity of use for the twenty-two abandoned houses were collected in the field and input into a geographic information system (GIS). All spatial data analyses were conducted in ArcMap 10.6 and ArcGIS Online (Esri: Redlands, CA, USA). We spatially referenced houses by obtaining GPS coordinates on-site (Figure 1). We systematically cataloged each site with a detailed scoring sheet (Appendix A). Scoring was conducted on-site and resulting data were input into the GIS. Intensity of use for the twenty-two sites was categorized as high (weekly/daily/constant use, $n=5$ ), medium (monthly use, $n=4$ ), low (yearly use, $n=2)$, or none $(n=11)$ with numerical scores of 3, 2, 1, and 0, respectively. Intensity was based on Sandin's familiarity with site usage, gained over two years of repeated visits to track traces of use and to speak with homeless persons on-site, correlated with other interviews with homeless and point-in-time count data. Prospect and refuge characteristics were each coded on a 1 (low) to 5 (high) scale, then summed per site to obtain 
prospect-refuge values. Accessibility variables included absence of locks and evidence of open doors and windows. The variables were scored as present (1) or absent (0) and then summed, so that a higher score $($ maximum $=3)$ indicates greater ease of access. Attractiveness variables included prominent vegetation proximate to the structure, roof and/or wall damage, nearby abandoned structures, and existence of old, weathered plywood over windows or doors. Each site was given one-half a point for each type of vegetation present, one-half a point for each type of structural damage, one point for having other abandoned houses nearby, and one point for having old plywood, then summed per site (maximum $=5)$. Higher scores indicate a greater degree of attractiveness.

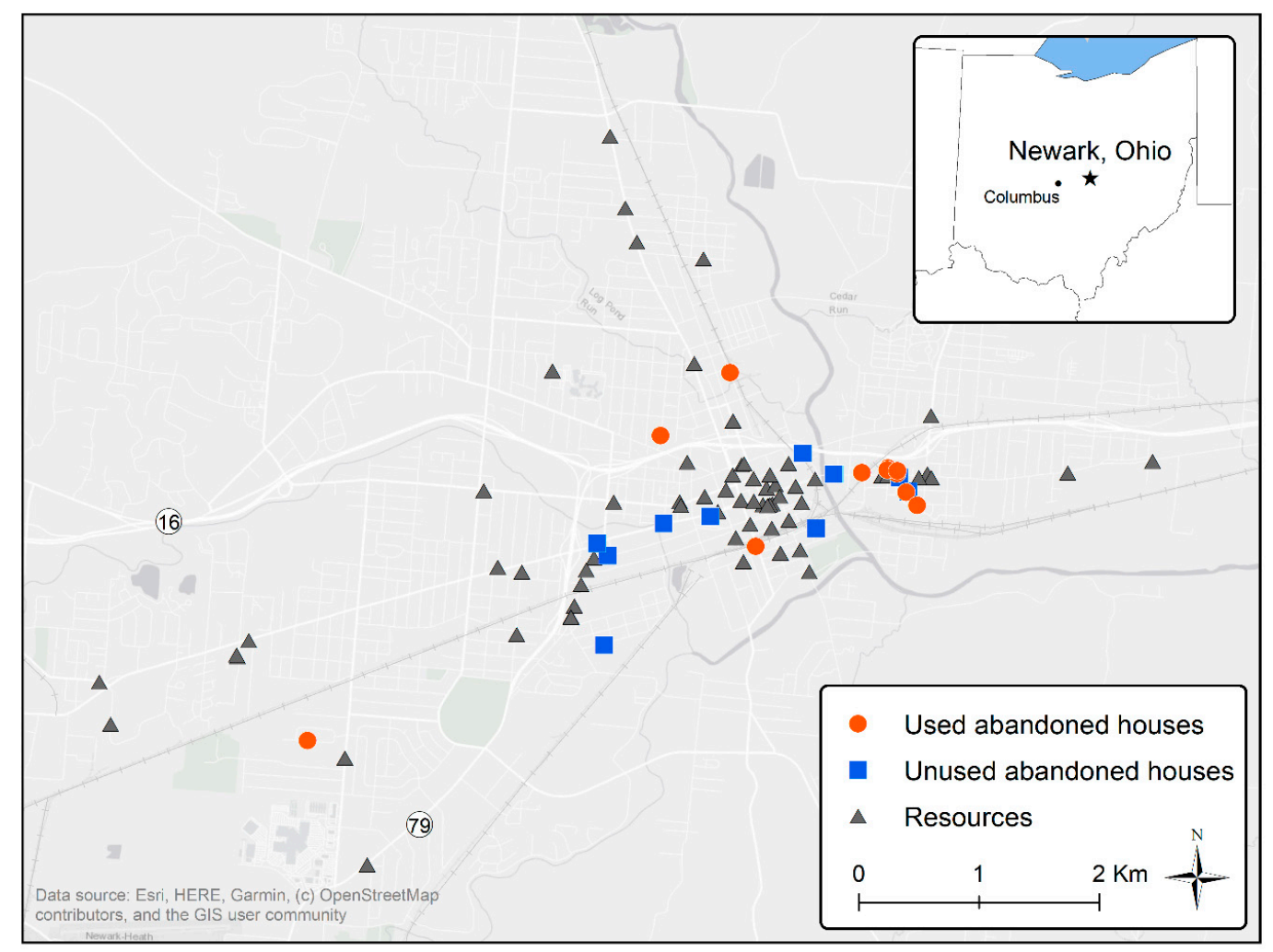

Figure 1. Location of twenty-two abandoned houses examined in Newark, Ohio, including structures utilized (red circles) and not utilized (blue squares) by homeless persons. Triangles indicate locations of resources included in the analyses.

Resources commonly used by Newark's homeless (e.g., food, health care, alcohol, social services) were identified in consultation with LCCH. Street addresses for the resource locations ( $n=103$, Table 1$)$ were geocoded into the GIS (Figure 1) in order to explore geographical distributions of abandoned housing in relation to available resources. We calculated the mean center, standard distance, and point density of resources. We quantified resource proximity using spatial joins and point distance analyses to determine distances between an abandoned house and all resources within 400 and $8000 \mathrm{~m}$. The distances are based on the standard reasonable walking distance of one-quarter mile for pedestrians (e.g., [33,34]) and a five-mile median daily walking distance of homeless persons [35]. (For ethnographic studies of urban homeless mobility, see [36-38].) We utilized walking distance areas rather than standard 'as-the-crow-flies' circular buffers since the walking distance area analysis more closely resembles human walking patterns by employing pedestrian accessible networks (e.g., paths and roads). We used Pearson correlation analyses to evaluate relationships between intensity of use and prospect-refuge, accessibility, attractiveness, and resource proximity variables. We compared differences between used and unused abandoned houses using $t$-tests. The small sample size of houses 
has the potential to yield outliers and impact the quality of statistical results, which informed our choice to utilize both quantitative and qualitative means of assessing these data.

Table 1. Types and amounts of resources available to the homeless population of Newark, Ohio.

\begin{tabular}{cc}
\hline Resource & No. of Resources \\
\hline Food sources & 30 \\
Emergency shelters/warm interiors & 15 \\
Alcohol/drugs & 12 \\
Employment services & 8 \\
Information/social opportunities & 8 \\
Housing resources & 7 \\
Supplies & 7 \\
Financial/legal services & 6 \\
Mental health/substance abuse services & 6 \\
Health care & 4 \\
\hline
\end{tabular}

\section{Results}

\section{1. $H_{1}$ : Prospect and Refuge Predict Abandoned House Site Selection}

We hypothesized that sites with both high refuge and high prospect are the most intensely used. Mean prospect scores were significantly different between used and unused abandoned houses $(t=6.71$, $p<0.0001$ ). Houses used by homeless persons had little to no visibility (mean prospect score $=1.91$ ) whereas unused houses had moderate sight lines (mean prospect score $=3.00$ ). Higher intensity sites had lower prospect scores $(r=-0.90, p<0.0001)$, which is counter to our hypothesis. All but one of the twenty-two sites were rated with a high refuge score, and there was no statistically significant difference between the means of used and unused sites, indicating that in general for this dataset abandoned houses provide a high degree of refuge.

\section{2. $\mathrm{H}_{2}$ : Accessibility is a Necessary Attribute of Abandoned Houses Used as Homeless Shelters}

The mean accessibility score for used abandoned houses was significantly different than that for unused abandoned houses $(t=-3.01, p=0.007$, Figure 2$)$. Furthermore, intensity of use was correlated with accessibility $(r=0.60, p=0.004)$ indicating that well-used sites were more accessible than unused abandoned houses, which supports our hypothesis.

\section{3. $H_{3}$ : Evidence of (un)attractiveness Serves as Essential Cues to Homeless Shelter-Seekers}

The $t$-tests and correlation analyses of attractiveness scores were statistically insignificant, indicating that the data do not support our hypothesis that desirability cues for abandoned structures are related to a site's intensity of use. It is likely that attractiveness plays only a minor role in determining site choice, and that many other interrelated variables also play into the decision.

\section{4. $H_{4}$ : Homeless People Are More Likely to Find Shelter That is Proximate to Basic Survival Resources}

All but one of the twenty-two abandoned houses were within the standard distance of resources $(1.74 \mathrm{~km}$, Figure 3). Eleven used sites and ten unused sites had resources within their 400-meter walking area buffers (Figure 4, Table 2). High and medium intensity sites were proximate to the densest core of resources. Of the resource categories, food $(r=-0.30, p=0.009)$ was significantly correlated with intensity of use of abandoned houses. In other words, higher intensity sites were closer to food resources (e.g., free lunches, food pantries, dumpster, cheap food sources) than unused sites (Figure 4), thereby supporting our hypothesis. 


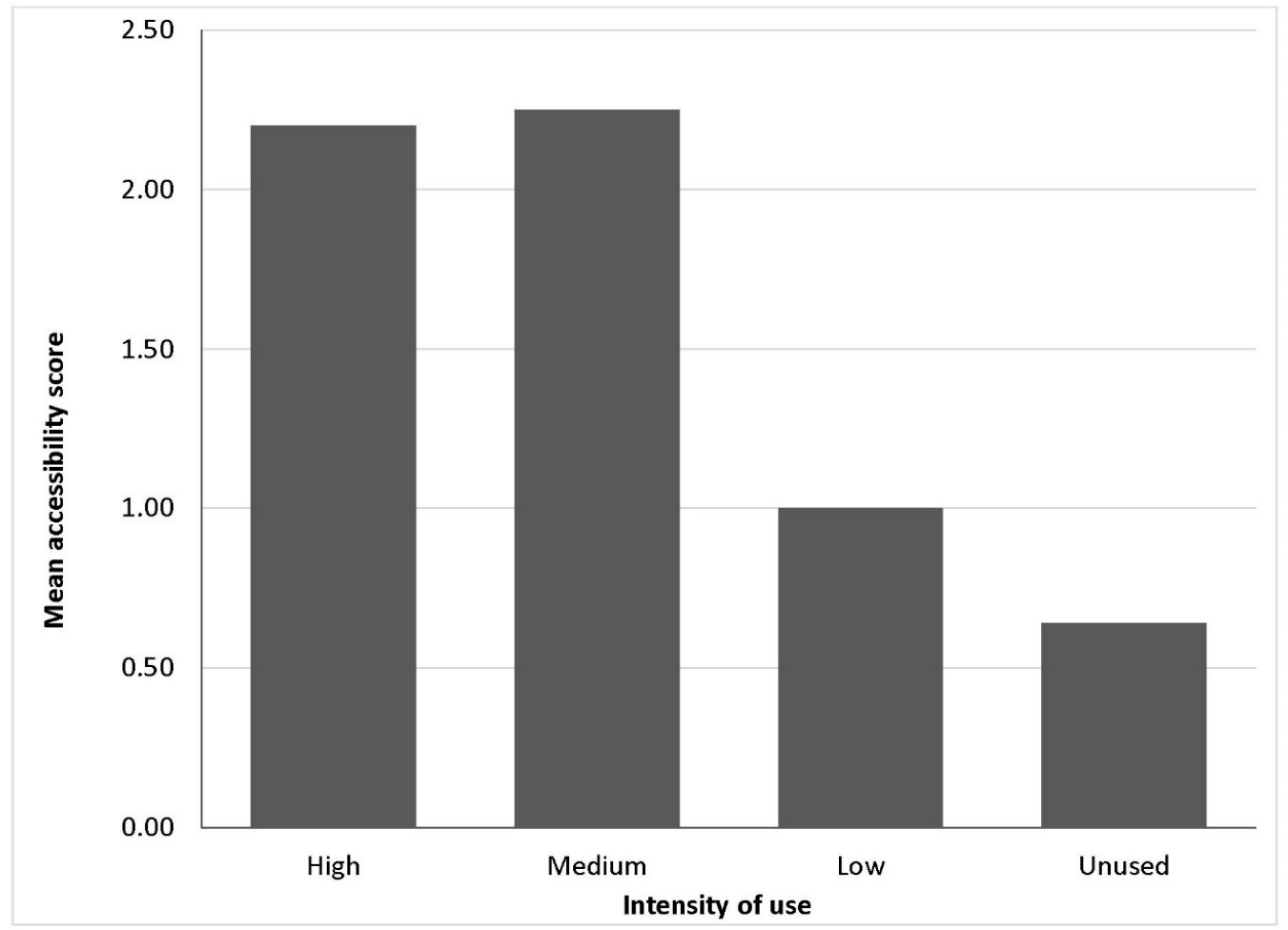

Figure 2. Mean accessibility scores for eleven abandoned houses with high, medium, and low intensity of use by homeless persons and eleven abandoned houses not used by homeless persons. A higher score (maximum $=3$ ) indicates greater ease of access.

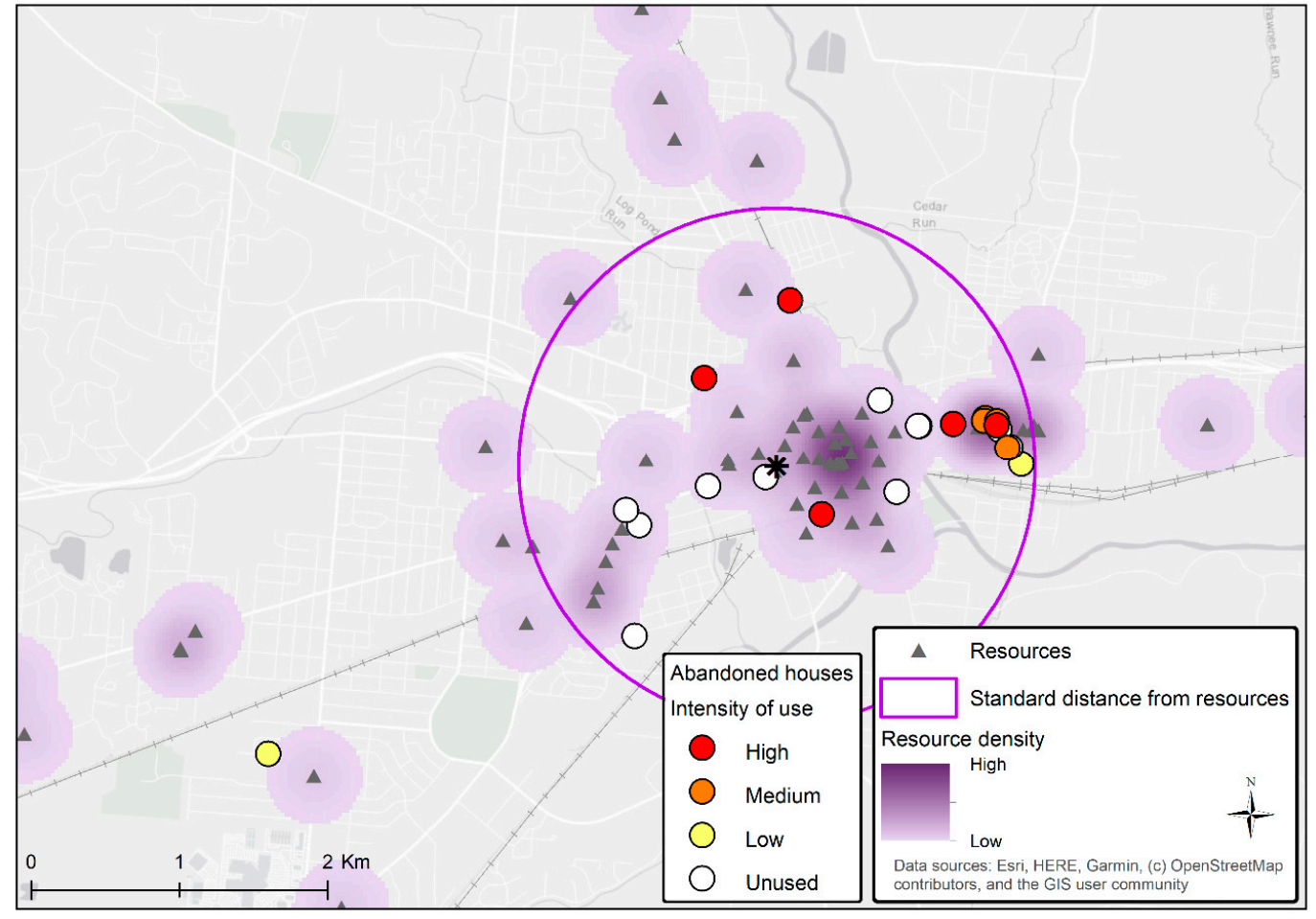

Figure 3. Map showing patterns of resource density in relation to intensity of use for twenty-two abandoned houses in Newark, Ohio. 


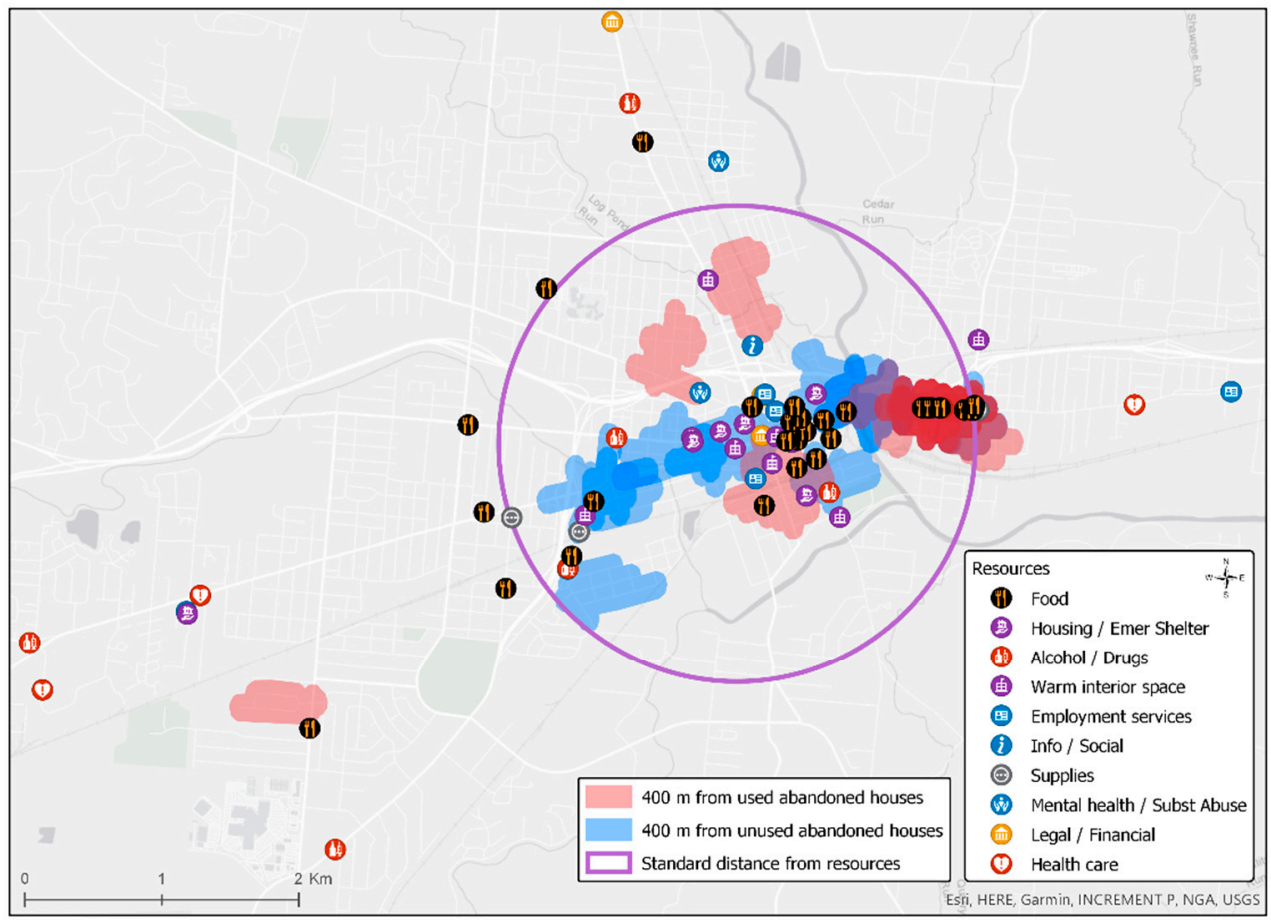

Figure 4. Map showing categories of resources juxtaposed against overlapping 400-meter walking distance buffers around used and unused abandoned houses.

Table 2. The percentage of resources within 400-meter and 8000-meter walking distance areas of used and unused abandoned houses.

\begin{tabular}{cccc}
\hline Site ID & Site Intensity & \% Resources within $\mathbf{4 0 0} \mathbf{~ m}$ & $\mathbf{\%}$ Resources within $\mathbf{8 0 0 0} \mathbf{~}$ \\
\hline 17 & High & 19 & 100 \\
23 & High & 18 & 100 \\
21 & High & 13 & 100 \\
1 & High & 1 & 100 \\
2 & High & 1 & 100 \\
24 & Medium & 18 & 100 \\
25 & Medium & 18 & 100 \\
36 & Medium & 18 & 100 \\
38 & Medium & 18 & 100 \\
26 & Low & 8 & 100 \\
44 & Low & 1 & 99 \\
49 & Unused & 18 & 100 \\
50 & Unused & 18 & 100 \\
52 & Unused & 11 & 100 \\
55 & Unused & 8 & 100 \\
54 & Unused & 7 & 100 \\
60 & Unused & 6 & 100 \\
58 & Unused & 4 & 100 \\
53 & Unused & 3 & 100 \\
56 & Unused & 1 & 100 \\
57 & Unused & 1 & 100 \\
59 & Unused & 0 & 100 \\
\hline
\end{tabular}

\section{Discussion}

Our findings offer interesting opportunities, both as academic researchers and as advocates for the well-being of disadvantaged populations in our communities. The spatial behavior of Newark's homeless teaches us important lessons about usage of abandoned houses. To bring these perspectives 
to fruition, our results elicit a series of new patterns that might join the design recommendations in A Pattern Language [30]. We offer one pattern for each of our four hypotheses, seeking to build on the results just outlined.

\subsection{Pattern 1: Hiding Places}

Without a decent place to hide, people will not continue using a site. It is human nature to be frightened when lacking essential information about possible threats, a fundamental value of prospect. Lack of refuge creates similar problems: no protection from the elements, nowhere to hide, no sense of comfort and almost certainly a physically difficult environment in which to sleep, stay warm and dry, or even to eat.

We found evidence for the value placed on refuge, while prospect appeared to be a lower priority among our sites. The findings may be indicative of the lack of diversity of shelter type-abandoned houses do not differ greatly in terms of prospect or refuge but may differ importantly from a less structured shelter. When camping out under a highway bridge, sight lines are invariably poor, with structural metal and concrete forming a visually opaque barrier. Perceptions of prospect/refuge may not apply to homeless use of abandoned houses, but we assert that the hypothesis is applicable when investigating all sheltering options available to a particular homeless population.

Sites providing shelter from the elements, noise, strangers, watchers, and enemies are critical to survival. Vigilance is secondary but important as well. Urban nature provides an ideal opportunity to bring these qualities back into the city environment. Trees and landscaped areas provide protection and, often, a way of seeing that affords the viewer a sense of being hidden. Vegetation complements other forms of refuge: arrangements of buildings, overhangs, bridge abutments, and other physical structures. We observed many examples of this opportunity, from a safe alley in a residential area to a wooded area along a railroad right-of-way (Figure 5). These are both micro-regions rarely traversed by people unfamiliar with the territory, and a low priority for cruiser-based police rounds.
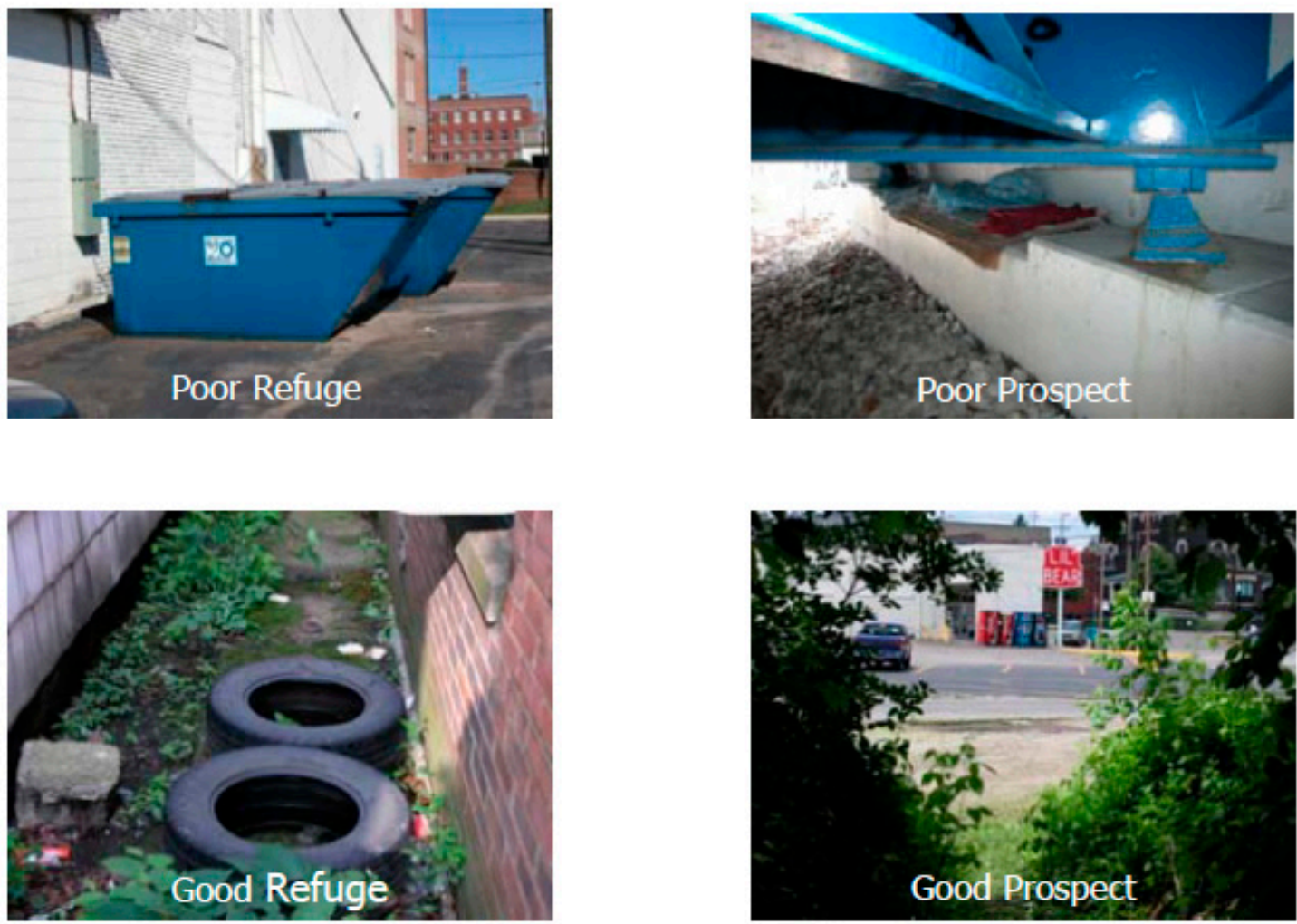

Figure 5. Examples of homeless sites offering good prospect or refuge. Photography: K. Sandin. 


\subsection{Pattern 2: Welcome Mat}

If an abandoned structure appears difficult to get into, then it will not be used. Any potential shelter offers clear signs of use, possible dangers, and availability. The challenge in accessibility is finding easy, secure opportunities for entry. For the homeless person, personal energy conservation is critical: No one who is hungry, sleep-deprived, mentally strained, and lacking in basic support systems is likely to exert a lot of energy gaining access to an abandoned structure. The kind of vulnerability and exposure a homeless person likely feels would produce learned responses that are adaptive. The amount of time required to enter a structure becomes a snap calculation, and awareness of accessibility cues would be expected to gain acuity as one lacks regular shelter. Given a choice between an empty building with padlocks and boarded windows, versus one with a door standing ajar, the invitation of the latter structure is obvious.

In our study, abandoned buildings offering strong accessibility cues were used much more often (Figure 6). Cues of availability may not be obvious to the passer-by. Some buildings appear inaccessible at the front, but have received less attention on the sides or the rear, where a smashed window may be sufficient to afford a point of access. Buildings with doors and windows shrouded by foliage offer both potential access and the benefit of refuge. Our research suggested a strong correlation between these accessibility cues and the probability of habitation in abandoned structures.
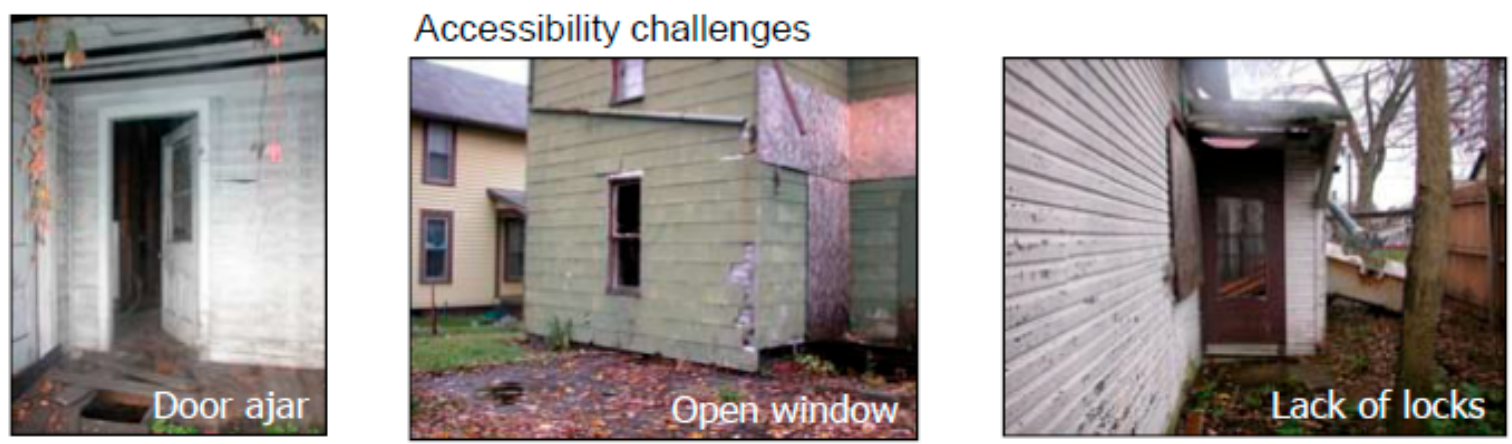

Figure 6. Examples of accessibility cues among abandoned houses in Newark, Ohio. Photography: K. Sandin.

It is reasonable to expect that homeless individuals will notice the "welcome mat" of easy access, and will inhabit those spaces offering the easy way in. As abandoned buildings are girded against unlawful entry, homeless people will be forced to gain access through more violent means-breaking windows, kicking down doors, using tools to pry open locks, and generally retreating to more desperate measures in order to find a temporary shelter.

\subsection{Pattern 3: Shelter (Un)becoming}

Signs of care create unattractive sites for homeless individuals. While accessibility cues provide essential information about entry, cues regarding attractiveness alert the potential inhabitant about the viability of a space for longer-term use. The homeless perceive building cues in ways that are sometimes inverse to perceptions of non-homeless people: Neglect may be a conspicuous blemish on a building for someone who has regular shelter, but a homeless person may look at the same building with interest, noting that the chances of being bothered are smaller in that space than somewhere showing signs of regular care.

Behavioral patterns associated with attraction are similar to those of accessibility but are likely to be more subtle and less visceral for a homeless person. Instead of worrying about having a roof over one's head for the night and the prospects of getting into a building, the issues here are connected with the repeatability of using a squat, the likelihood that another homeless person might have 
assumed temporary ownership, and the cues of surveillance or property management that could prove inconvenient or disruptive upon continued use of the site in question.

We found mixed results in terms of site attractiveness. This led us to wonder both about interaction effects (access and attraction) and about our attractiveness measures. The building that scored strongly on attractiveness might appear inaccessible, reducing the chances of its use despite evidence that it would be viable. As we did not analyze these data in greater detail, the question remains unanswered, and deserves further investigation. Three specific attraction factors merit attention as part of the development of this pattern: weathered wood, roof repair, and overgrown vegetation (Figure 7). New plywood on windows/doors suggests some degree of maintenance and official interest, discouraging a site's use as a shelter. Old plywood sends the message of negligence and makes a site attractive. Roof/exterior walls in disrepair offer immediate cues of an uninhabited structure not under the watchful eye of the owner or manager. Unmanaged, proliferating vegetation indicates a sense of safety that a site would lack if it were mowed and tidy. Overgrown vegetation cues are especially valuable for the homeless person seeking a highway overpass, bridge, or natural area of growth as shelter. This offers a useful link to the earlier discussion of prospect-refuge and patterns associated with a sense of safety in hiding.
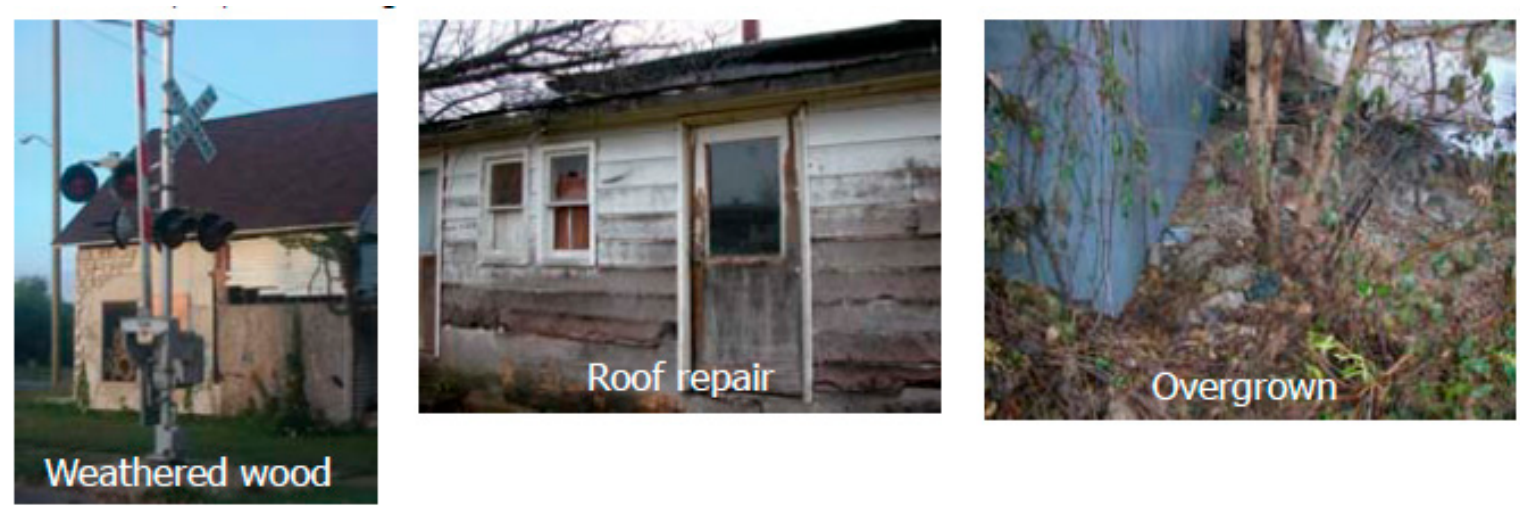

Figure 7. Weathered wood, roof disrepair, and overgrown vegetation provide evidence of neglect in abandoned houses. Photography: K. Sandin.

Our analysis of site attractiveness focused on attributes of an abandoned house. Although outside the scope of the current data set, future research might examine the neighborhood physiognomy surrounding each used and unused homeless site. For example, investigating the distribution of low-income housing and/or rental costs [39], mapping the density of vacant houses [40], or three-dimensional mapping of the urban fabric (e.g., vegetation predominance/height, building height, closeness of streets to buildings, see [41]) in relation to used and unused homeless sites might provide additional insight regarding the attractiveness of a site.

\subsection{Pattern 4: Proximity to Resources}

Homeless people's quality of life suffers if they cannot find easy shelter near services needed for basic functioning. These services can include nourishment, medical assistance, heat, shade, alcohol, drugs, clothing, and materials for the construction of temporary shelter. The homeless are no different from mainstream society in a desire to have their needs met efficiently, and some homeless people have spent parts of their lives in situations where they had the relative conveniences of the sheltered population, so their expectations may well be similar to mainstream society. However, regardless of personal history, we expect the homeless would want to travel as little as possible for the most essential requirements of living. For those in an addictive cycle, the proximity of drugs or alcohol may be primary in this list. For others who dumpster-dive for food, the most wasteful grocery store may be an essential resource. This builds on the base of perceived distance research [42]. Though not the 
purview of this research, it is likely that the mental maps and decision choices of the homeless match up with this approach as well [43]. The walking distance area buffers used for the resource proximity analyses in this study are constrained to existing infrastructure networks of roads and sidewalks. Future research might include a network of informal pedestrian pathways (e.g., shortcuts across green spaces, see [44]).

\subsection{Recommendations}

Our findings suggest that for the Newark homeless population utilizing abandoned housing, accessibility to food is important in shelter site location. Other studies of resource distribution in relation to homeless distribution find that food access, in addition to employment and public medical care, has a significant impact on the location of homeless sites [45]. As a first step, communities would benefit from establishing similar measurements and then determine both the stability and the availability of those service options. Many communities already have official recommendations to locate homeless shelters within walking distance of essential services in order to reduce extraneous transportation demands. Instead of forcing the homeless to shift their daily activities to a location matching the needs of public officials, shelters and other services provided by the government should be in areas proximate to the people receiving these services.

This study seeks to uncover spatial patterns of habitation for the homeless population in a mid-sized city, to understand their shelter requirements better and ultimately to enhance the policies and programs communities establish regarding homelessness. If our research can inform these processes through a better understanding of homeless site use pattern behavior, then the potential for effective community-building opportunities might be enhanced as well. Certainly, we are much in favor of preventative efforts that reduce the chances someone becomes homeless in the first place, and programs that assist homeless persons with securing permanent housing (e.g., Housing First programs [46]), but our project starts with the premise that people who lack regular shelter merit careful attention.

While squatting is a de facto solution to homelessness in some cities, issues of policing, legality, urban decay, and neighborhood issues prevail. Considering our concerns regarding public policy responses to this research, we encourage administrators, public officials, non-profit agencies, and others involved in the multiple layers of homelessness to consider the following vignette. Imagine that an urban center was to allocate a few small parcels of land in the downtown area to establish vest-pocket parks. These parcels might be locations of abandoned housing, interstitial spaces that have gone without clear uses, or sites that might otherwise be chosen for their proximity to existing service agencies. Let us imagine that these parks serve as public open space that supports and enhances human activity within natural features by incorporating Alexander's fifteen fundamental properties of wholeness for functional and sustainable design [47]. For example, plantings of trees and shrubs would create segmented areas (local symmetries) and separation of activities (boundaries) to unite strong centers, engage positive space, and promote interconnectedness among multiscale geometries of design [47]. The proposed space, Vignette Park, has three uncommon properties: its space, legal enforcement properties, and inherent trust.

Vignette Park encourages homeless people to find refuge. Its roofed picnic shelters become overnight squats, its vegetation provides prospect and refuge, and its arrangement is designed specifically to provide shelter. The shelters could be enclosed on two sides, with landscaping to create windbreaks. In addition, the shelters could be accessed by smooth, hard pathways allowing bikes and shopping carts to be kept close by, offering individuals rest knowing their belongings are secure. By designing the park according to actual behavioral patterns, we begin to speak the language of their adaptive use. If we get it right, then we will match their adaptive responses to the cues and signals they acquire from their environment, and they will be more likely to accept and use this temporary refuge.

Another fundamental feature of Vignette Park is its policing. Between 12:00-6:00 a.m., the enforcement of vagrancy (but not other crimes) is relaxed in this space, so that homeless people 
gain some rest without the vigilance that comes with occupying their usual squats. Clearly, there is a quid pro quo built into this unusual policing: The people who take advantage of this site would not be permitted to violate other laws-overt substance abuse, open container, etc.-and would be expected to make sure the Park is (relatively) pristine each morning, so that other people will want to use it during the day. This approach is similar to the hybrid urban space described by Perry [12] and the safe car parking program in San Diego [48]. Perhaps tents or other ephemeral shelters could be erected, but they would need to be dismantled by morning to avoid a common flashpoint with law enforcement-permanent structures in public places. Dogs owned by homeless individuals would be one of many issues to be negotiated. Police patrols and on-site non-governmental organization support would be needed to ensure that the nighttime management of the Park could proceed without difficulty. It is likely that Vignette Park's management would need to be framed as an inter-agency homeless outreach program.

Finally, Vignette Park would be created to improve trust [49]. Some of the socially inappropriate behavior manifested among the homeless arises because of distrust between the homeless and police [50]. The homeless are far less likely to destroy property and damage public places if they know their rights are going to be protected-if they have a safe zone to which they may retreat [51]. Police officers may find their job far more comprehensible too, if they have clarity about enforcement of public laws in a coherent and consistent manner: Often, they are forced to make difficult judgment calls regarding a trespassing homeless person versus a non-homeless person caught in the same behavior [52]. Developing a homeless outreach framework would place social workers and NGO's on equal footing with law enforcement. Communication and the provision of housing access, treatment, and other social service needs would be as much a part of the effort as law enforcement. Best-case scenarios might include nightly presence of a vehicle operated by an NGO where homeless persons congregate, staffed by outreach workers and equipped with food, water, blankets, and other items as climate and season dictate. In this way, by setting temporal and spatial boundaries with the help of a park facility and by hands-on, collaborative management and social resource provision, the standards of trust may expand in both directions. We recognize this vignette does not work equally well in all settings. However, it behooves planners, city administrators, and other public officials to think creatively and proactively about homelessness.

\section{Conclusions}

Our findings suggest that there are systematic spatial patterns in the use of space by Newark's homeless population, and several opportunities for planners, developers, city officials, housing advocates, and others to take stock of the realities of homeless living. While some potential readers might see these findings as a call to board up every building and prevent the homeless from seeking shelter, we see that as a foolish response: Until proactive steps are taken to ensure that homelessness does not exist, there will be people who need temporary shelter, and they will find ways to survive. In an environment of accelerating rates of home foreclosure, public officials should realize that the audience to whom these ideas apply is only expanding. Perhaps the best policy-however unofficial—that a city might adopt is to enhance opportunities for the homeless to procure shelter where they can be most secure, where they can feel safe, and where they can struggle the least to survive. Instead of banning the homeless from downtown areas, expending resources on police surveillance to impede their travel, and undermining their already-fragile dignity, let us instead learn from their patterns. Imagine the potential if we craft more flexible and humane options for the homeless, with spatial solutions that enhance their own efforts to gain traction on their livelihoods.

Author Contributions: Conceptualization, A.K., K.S. and K.D.; data curation, K.S., S.K.M. and K.D.; formal analysis, K.S. and K.D.; investigation, K.S., S.K.M. and K.D.; methodology, A.K., K.S. and K.D.; project administration, A.K.; validation, A.K.; writing—original draft, A.K., K.S., S.K.M. and K.D.; writing—review \& editing, A.K., K.S. and K.D.

Funding: This research received no external funding. 
5. Alexander-Eitzman, B.; Pollio, D.E.; North, C.S. The neighborhood context of homelessness. Am. J. Public Health 2013, 103, 679-685. [CrossRef]

6. Enwezor, O. Popular sovereignty and public space: David Adjaye's architecture of immanence. In David Adjaye. Making Public Buildings: Specificity, Customization, Imbrication; Allison, P., Ed.; Thames and Hudson: New York, NY, USA, 2006; pp. 8-12.

7. Deleuze, G.; Guattari, F. A Thousand Plateaus; The Athlone Press: London, UK, 1988; p. 10.

8. Lefebvre, H. The Production of Space; Nicholson-Smith, D., Translator; Blackwell Publishing: Oxford, UK, 1991; pp. 36-42, 73.

9. Hilal, S.; Petti, A. Permanent Temporariness; Axel, N., Nadotti, M., Eds.; Al Barbary, I.; Recchia, F., Translators; Art and Theory Publishing: Stockholm, Sweden, 2018; pp. 122-130.

10. Rosenthal, R.; Foscarinis, M. Responses to homelessness: Past policies, future directions, and a right to housing. In A Right to Housing: Foundation for a New Social Agenda; Bratt, R.G., Stone, M.E., Hartman, C., Eds.; Temple University Press: Philadelphia, PA, USA, 2006; pp. 316-339.

11. Giesler, M.A. The collaboration between homeless shelters and public libraries in addressing homelessness: A multiple case study. J. Libr. Adm. 2019, 59, 18-44. [CrossRef]

12. Perry, S. Urban hybrid space and the homeless. Ethnography 2013, 14, 431-451. [CrossRef]

13. Sandin, K. Crates, kegs, and belonging: Making places for identity in a Midwestern back alley. Int. J. Des. Soc. 2013, 6, 1-21. [CrossRef]

14. Johnsen, K.; May, J.; Cloke, P. Imag(in)ing 'homeless places': Using auto-photography to (re)examine the geographies of homelessness. Area 2008, 40, 194-207. [CrossRef]

15. Snow, D.A.; Anderson, L. Down on Their Luck: A Study of Homeless Street People; University of California Press: Berkeley, CA, USA, 1993; p. 405.

16. Snow, D.A.; Mulcahy, M. Space, politics, and the survival strategies of the homeless. Am. Behav. Sci. 2001, 45, 149-169. [CrossRef]

17. Marr, M.D.; Deverteuil, G.; Snow, D.A. Towards a contextual approach to the place-homeless survival nexus: An exploratory case study of Los Angeles County. Cities 2009, 26, 307-317. [CrossRef]

18. Speer, J. "It's not like your home": Homeless encampments, housing projects, and the struggle over domestic space. Antipode 2016, 49, 517-535. [CrossRef]

19. Wagner, D. Checkerboard Square: Culture and Resistance in a Homeless Community; Westview Press: Boulder, CO, USA, 1993; p. 216.

20. Stuart, F. From 'rabble management' to 'recovery management': Policing homelessness in marginal urban space. Urban Stud. 2013, 51, 1909-1925. [CrossRef]

21. Darrah-Okike, J.; Soakai, S.; Nakaoka, S.; Strane, T.; Umemoto, K. “It was like I lost everything": The harmful impacts of homeless-targeted policies. Hous. Policy Debate 2018, 28, 1-17. [CrossRef]

22. Langegger, S.; Koester, S. Invisible homelessness: Anonymity, exposure, and the right to the city. Urban Geogr. 2016, 37, 1030-1048. [CrossRef]

23. Mitchell, D. People's Park again: On the end and ends of public space. Environ. Plan. A Econ. Space 2016, 49, 503-518. [CrossRef]

24. Mitchell, D. The Right to the City: Social Justice and the Fight for Public Space; The Guilford Press: New York, NY, USA, 2003; p. 270.

25. Wright, T. Out of Place: Homeless Mobilizations, Subcities, and Contested Landscapes; SUNY Press: Albany, NY, USA, 1997; p. 408.

26. Maxwell, A.H. A home by any means necessary: Government policy on squatting in the public housing of a large mid-Atlantic city. In There's No Place Like Home: Anthropological Perspectives on Housing and Homelessness in the United States; Dehavenon, A.L., Ed.; Bergin and Garvey: Westport, CT, USA, 1996; pp. 67-80.

27. Phillips, A.; Hamilton, S. Huts for the homeless: A low-technology approach for squatters in Atlanta, Georgia. In There's No Place Like Home: Anthropological Perspectives on Housing and Homelessness in the United States; Dehavenon, A.L., Ed.; Bergin and Garvey: Westport, CT, USA, 1996; pp. 81-105.

28. Rameau, M. Take Back the Land: Land, Gentrification, and the Umoja Village Shantytown, 2nd ed.; AK Press: Oakland, CA, USA, 2012; p. 140.

29. Hull, J. Settling Homeless Families in Vacant Homes. Available online: https://shelterforce.org/2018/05/02/ take-back-the-land/ (accessed on 28 May 2019). 
30. Alexander, C.; Ishikawa, S.; Silverstein, M.; Jacobson, M.; Fiksdahl-King, I.; Angel, S. A Pattern Language: Towns, Buildings, Construction; Oxford University Press: New York, NY, USA, 1977; p. 1171.

31. Broadbent, G. Emerging Concepts in Urban Space Design; Van Nostrand Reinhold: London, UK, 1990; p. 392.

32. Appleton, J. The Experience of Landscape; Wiley: New York, NY, USA, 1975; p. 293.

33. Miyake, K.K.; Maroko, A.R.; Grady, K.L.; Maantay, J.A.; Arno, P.S. Not just a walk in the park: Methodological improvements for determining environmental justice implications of park access in New York City for the promotion of physical activity. Cities Environ. 2010, 3, 1-17. [CrossRef] [PubMed]

34. Yang, Y.; Diez-Rouz, A.V. Walking distance by trip purpose and population subgroups. Am. J. Prev. Med. 2012, 43, 11-19. [CrossRef] [PubMed]

35. To, M.J.; Brothers, T.D.; Van Zoost, C. Foot conditions among homeless persons: A systematic review. PLoS ONE 2016, 11, e0167463. [CrossRef] [PubMed]

36. Wolch, J.R.; Rowe, S. On the streets: Mobility paths of the urban homeless. City Soc. 1992, 6, 115-140. [CrossRef]

37. Jocoy, C.L.; Del Casino, V.J. Homelessness, travel behavior, and the politics of transportation mobilities in Long Beach, California. Environ. Plan. A 2010, 42, 1943-1963. [CrossRef]

38. Šimon, M.; Vašát, P.; Poláková, M.; Givas, P.; Daňková, H. Activity spaces of homeless men and women measured by GPS tracking data: A comparative analysis of Prague and Pilsen. Cities 2019, 86, 145-153. [CrossRef]

39. Glynn, C.; Fox, E.B. Dynamics of homelessness in urban America. Ann. Appl. Stat. 2019, 13, 573-605. [CrossRef]

40. Anti-Eviction Mapping Project. Vacant Units, San Francisco. Available online: https://www.antievictionmap. com/vacant (accessed on 11 June 2019).

41. Hermosilla, T.; Palomar-Vázquez, J.; Balaguer-Beser, Á.; Balsa-Barreiro, J.; Ruiz, L.A. Using street based metrics to characterize urban typologies. Comput. Environ. Urban Syst. 2014, 44, 68-79. [CrossRef]

42. McCormack, G.R.; Gavin, R.; Cerin, E.; Leslie, E.; Du Toit, L.; Owen, N. Objective versus perceived walking distances to destinations: Correspondence and predictive validity. Environ. Behav. 2008, 40, 401-425. [CrossRef]

43. Hannes, E.; Janssens, D.; Geert, W. Does space matter: Travel mode scripts in daily activity travel. Environ. Behav. 2009, 41, 75-100. [CrossRef]

44. North, C.S.; Wohlford, S.E.; Dean, D.J.; Black, M.; Balfour, M.E.; Petrovich, J.C.; Downs, D.L.; Pollio, D.E. A pilot study using mixed GPS/narrative interview methods to understand geospatial behavior in homeless populations. Community Ment. Health J. 2017, 53, 661-671. [CrossRef] [PubMed]

45. Suzuki, W. What determines the spatial distribution of homeless people in Japan? Appl. Econ. Lett. 2008, 15, 1023-1026. [CrossRef]

46. Padgett, D.; Henwood, B.F.; Tsemberis, S.J. Housing First: Ending Homelessness, Transforming Systems, and Changing Lives; Oxford University Press: New York, NY, USA, 2016; p. 228.

47. Alexander, C. The Nature of Order: An. Essay on the Art of Building and the Nature of the Universe, Book 1-The Phenomenon of Life; Center for Environmental Structure: Berkeley, CA, USA, 2002; p. 476.

48. Dreams for Change. Available online: https://www.dreamsforchange.org/the-safe-parking-program/ (accessed on 30 May 2019).

49. Zakrison, T.L.; Hamel, P.A.; Hwang, S.W. Homeless people's trust and interactions with police and paramedics. J. Urban. Health 2004, 81, 596-605. [CrossRef] [PubMed]

50. Robinson, T. No right to rest: Police enforcement patterns and quality of life consequences of the criminalization of homelessness. Urban. Aff. Rev. 2019, 55, 41-73. [CrossRef]

51. Herzog, T.R.; Rector, A.E. Perceived danger and judged likelihood of restoration. Environ. Behav. 2009, 41, 387-401. [CrossRef]

52. Walby, K.; Lippert, R. Spatial regulation, dispersal, and the aesthetics of the city: Conservation officer policing of homeless people in Ottawa, Canada. Antipode 2012, 44, 1015-1033. [CrossRef]

(C) 2019 by the authors. Licensee MDPI, Basel, Switzerland. This article is an open access article distributed under the terms and conditions of the Creative Commons Attribution (CC BY) license (http://creativecommons.org/licenses/by/4.0/). 